\title{
“The Duty to Prevent" during an epidemic situation like 2015 Korean MERS outbreak
}

\author{
Jong-Myon Bae \\ Department of Preventive Medicine, Jeju National University School of Medicine, Jeju, Korea
}

Epidemiology, a core discipline in public health, identifies factors related to disease prevention and health promotion and applies these findings to local communities [1]. In particular, in cases of pandemic outbreak in local communities, epidemiology plays a central role in managing infected individuals and preventing disease propagation [2]. On May 20, 2015, after the confirmatory diagnosis of Middle East Respiratory Syndrome (MERS) [3], preventive medicine residents convened for an epidemic survey in early June 2015 to respond to worries about the risk of in-hospital infections spreading to local communities. On June 26 , an anonymous interview with a preventive medicine resident was published in the media [4].

The media article was published in the same setting as the issue of ethical responsibility imposed on the medical corps as the "duty to care" in the 2003 Severe Acute Respiratory Syndrome (SARS) outbreak case [5]. In this context, there is a need for preventive medicine specialists, including epidemiologists, to clarify ethical concepts at the level of "duty to prevent" during pandemics.

The obligations of epidemiologists in local communities include communication with local residents, explanation of outcomes, and performing appropriate disease prevention measures by disseminating results of epidemic surveys of pandemic-related measures to the local community wherever applicable [2]. This is similar to the duty of a clinician to treat infected individuals. Regarding the imposition of the "duty to treat" during a pandemic, Malm et al. [6] presented five underlying ethical prin-

Correspondence: Jong-Myon Bae

Department of Preventive Medicine, Jeju National University School of

Medicine, 102 Jejudaehak-ro, Jeju 63243, Korea

Tel: +82-64-755-5567, Fax: +82-64-725-2593, E-mail: jmbae@ jejunu.ac.kr

Received: Aug 9, 2015, Accepted: Aug 15, 2015, Published: Aug 15, 2015

This article is available from: http://e-epih.org/

(C) 2015, Korean Society of Epidemiology

(C) This is an open-access article distributed under the terms of the Creative Commons Attribution License (http://creativecommons.org/licenses/by/3.0/), which permits unrestricted use, distribution, and reproduction in any medium, provided the original work is properly cited. ciples: consent, implied consent, special training, reciprocity, and oaths and codes. This duty can be interpreted as the responsibility of preventive medicine specialists, as doctors accredited by the country, to play the professional role expected of them by local communities in critical situations [2]. And epidemic surveillance is the first task of preventive medicine specialists in their role of disease management [7].

Ethical obligations based on ethical principles should be differentiated from ethical virtues [2,8]. While obligations specify roles and responsibilities, virtues are the character traits underlying personal attitude and behavior in fulfilling a just cause [2, 8]. The major character traits required of epidemiologists are benevolence, honesty, prudence, excellence, and integrity [2]. Especially, solidarity and loyalty are additional character traits that are utmost important, as they ensure the trust of the local community [8].

However, these character traits cannot be acquired by education, and should be cultivated by individuals [9]. In this regard, specialist training programs should be help residents more efficiently carry out their "duty to prevent". Additionally, the proper methods for wearing and removing protective coveralls should be taught without fail during training so that specialists can protect themselves from infection. Along with these efforts, the most desirable attitude for bridging the ethical gap during a pandemic is the voluntary participation of the specialists [10].

\section{CONFLICT OF INTEREST}

The author has no conflicts of interest to declare for this study.

\section{SUPPLEMENTARY MATERIAL}

Supplementary material (Korean version) is available at http: //www.e-epih.org/. 


\section{REFERENCES}

1. McKeown RE, Weed DL, Kahn JP, Stoto MA. American College of Epidemiology Ethics Guidelines: foundations and dissemination. Sci Eng Ethics 2003;9:207-214.

2. American College of Epidemiology. Ethics guidelines 2000 [cited 2015 Aug 9]. Available from: http://www.acepidemiology.org/statement/ethics-guidelines.

3. Ki M. 2015 MERS outbreak in Korea: hospital-to-hospital transmission. Epidemiol Health 2015;37:e2015033.

4. Kang Y. An interview of MERS epidemic investigator: worry about infection risk. Pressian; 2015 Jun 26 [cited 2015 Aug 9]. Available from: http://www.pressian.com/news/article_print.html?no=127630 (Korean).
5. Singer PA, Benatar SR, Bernstein M, Daar AS, Dickens BM, MacRae SK, et al. Ethics and SARS: lessons from Toronto. BMJ 2003; 327:1342-1344.

6. Malm H, May T, Francis LP, Omer SB, Salmon DA, Hood R. Ethics, pandemics, and the duty to treat. Am J Bioeth 2008;8:4-19.

7. Reid L. Diminishing returns? Risk and the duty to care in the SARS epidemic. Bioethics 2005; 19:348-361.

8. Klopfenstein ML. Pandemic influenza and the duty to treat: the importance of solidarity and loyalty. Am J Bioeth 2008;8:41-43.

9. Weed DL, McKeown RE. Epidemiology and virtue ethics. Int J Epidemiol 1998;27:343-348.

10. Hodge JG Jr, Gable LA, Cálves SH. Volunteer health professionals and emergencies: assessing and transforming the legal environment. Biosecur Bioterror 2005;3:216-223. 